\title{
Synthesis
}

\section{Resilient Social Relationships and Collaboration in the Management of Social-Ecological Systems}

\author{
$\underline{\text { Abraham B. Nkhata }}^{1}$, Charles M. Breen ${ }^{1}$, and Wayne A. Freimund ${ }^{2}$
}

\begin{abstract}
This paper proposes and articulates a social relationships perspective of collaboration in the management of social-ecological systems (SESs). It provides a conceptual premise for understanding the dynamics of long-term social relationships that underlie collaborative processes. We argue that a resilience approach offers a better perspective for the study of change in long-term relationships. A conceptual framework based on the theories of resilience and social relationships is developed for analyzing the evolution of collaborative schemes. The essence of the framework is to facilitate understanding and building of resilient social relationships for effective collaboration through interpreting and managing relational change. We suggest that an analysis of resilient social relationships requires an understanding of the complexity and extent of relational change. The elements of a behavioral approach to relationships theory are discussed as a foundation for resilient social relationships. By incorporating the models of Holling (1995) and Cousins (2002) into a behavioral approach to relationships theory, the framework we propose can be used to determine the potential for change based on the amount of relational capital and the degree of relational connectedness in long-term social relationships.
\end{abstract}

Key Words: collaboration; relational capital; relational change; relational connectedness; resilience; social relationships; social-ecological systems

\section{INTRODUCTION}

Collaborative strategies are increasingly being promoted as a means of addressing problems associated with the management of socialecological systems (SESs) (Folke et al. 2002, Walker et al. 2002, Berkes et al. 2003). Although the concept of collaboration is not necessarily viewed as a panacea for all social-ecological problems (Hardy and Phillips 1998, Imperial 2005), the need for social actors to work together to enhance the capacity of SESs to cope with intermittent shocks has continued to receive enthusiastic attention (Berkes and Folke 1998, Blumenthal and Jannink 2000, Tompkins and Adger 2004, Newman and Dale 2005). Notwithstanding a growing appreciation of the importance of collaboration, little attention has been explicitly given to the dynamic long-term social relationships that underlie collaborative schemes in the management of SESs. Despite a few notable exceptions (such as Ostrom 1990, Imperial and
Kauneckis 2003), most studies have not given explicit attention to the changing nature of longterm social relationships. These relationships are usually characterized by processes through which collaborative actors influence each others' behaviors over a period of time to advance individual and shared goals (Axelrod 1984, Ostrom 1998). To understand such relationships, we need to understand the behavioral processes through which collaborative schemes evolve over time. Not surprisingly, perhaps, the behavior of actors over time is most commonly evidenced by implication rather than through specific and explicit application in research.

In this paper, we propose and articulate a conceptual framework based on theories of resilience and social relationships for analyzing the behavioral processes of dynamic long-term social relationships that underlie collaborative arrangements in the management of SESs. We argue that an analysis of such processes requires an understanding of the 
complexity and extent of relational change. The framework we propose can be used to determine the potential for relational change as well as to categorize relationships based on the amount of relational capital and degree of relational connectedness. These elements of a behavioral approach to relationships theory are proposed as a foundation for resilient social relationships. Not only can such a perspective help us better understand and improve dynamic collaborative schemes, but also it can assist us advance the integration of human behavioral sciences into SES research.

\section{CONCEPTUALIZING COLLABORATION AND RELATIONSHIPS}

Different authors use different ways to define collaboration (see Wood and Gray 1991, Hardy and Phillips 1998, Phillips et al. 2000, Kinnaman and Bleich 2004, Selin 2004). For the purposes of this paper, we conceive collaboration as a behavioral process that involves different actors working together to create more benefits than could be produced in unilateral settings (Hall 1995, Imperial and Kauneckis 2003, Kinnaman and Bleich 2004, Imperial 2005). This process is founded on longterm relationships through which actors influence each others' behavior over a period of time to advance common and individual interests (Ostrom 1998, Cousins 2002). The benefits advanced for collaborative efforts include reduced transactional costs (Wood and Gray 1991), greater socialecological resilience (Walker et al. 2002), enhanced performance (Imperial 2004), and improved governance (Imperial 2005). Following Bardach (2001) and Hardy and Phillips (1998), however, we do not view collaboration as a "fix-all" strategy for all social-ecological problems. Its significance and appropriateness will depend on a range of contextual, preferential, and contingency factors (Wondolleck and Yaffee 2000, Imperial 2005). Accordingly, actors operating in particular SESs may opt for any of the several strategies of engagement, such as toleratance, avoidance, compliance, contention, and contestation (Hall 1995, Huxham 1996, Hardy and Phillips 1998, Cousins 2002), to mention just a few.

The term relationship means the manner in which actors interact with other actors, be they persons, groups, communities, or organizations (Ford et al. 1998). The state of interactions evinces the mode in which actors behave toward each other. By behavior, we mean the way in which actors act or do the things they do (Hutchison 2003). Whereas consistent patterns of actions constitute behavior and consistent patterns of behavior make up a behavioral style (Hall 1995), a single interaction between actors is called an episode (Ford et al. 1998). Each episode is shaped by the history of interactions in a relationship, and ultimately exerts influence on the future of that relationship (Axelrod 1984). Interactions unfold over time as actors act, react, and react to reactions thereby yielding longterm relationships (Hakansson and Snehota 1995). Although actors cannot determine whether the relationships they engage in will be collaborative or not, they may not necessarily decide whether or not to have relationships with those with whom they interact. Actors establish relationships by merely interacting with others, whether or not those relationships are close, productive, troublesome, or calm. What matters is that each episode is affected by previous interactions (see also Axelrod 1984, Ford et al. 1998).

Although it is not the intention of this paper to engage in paradigmatic debates, broadly speaking two schools of thought that explicitly deal with relationships in social and behavioral sciences can be identified: the social exchange and network approaches. The social exchange approach, whose contribution is mainly attributed to Blau (1964), seeks to understand the underlying processes that engender social interactions between actors. It examines processes that regulate social relationships over time, and is premised on the understanding that human behavior is predisposed to maximizing benefits and minimizing costs (Emerson 1987). On the other hand, the network approach analyzes the structures that emerge and constrain social interactions (Granovetter 1985, Knoke 1990). It is typically founded on sociograms that illustrate the links among network members (Newman and Dale 2005). Following Blau (1987) and Granovetter (1990), however, this paper recognizes that the two approaches are both useful frameworks for studying important social phenomena such as relationships. Given that they provide contrasting and not necessarily comparative theoretical perspectives, they are based on different units and levels of analysis, and thus may use different concepts and tools. In a sense, the two approaches deal with different aspects of social life, and each tries to explain phenomena that the other assumes to be given. Thus, they are not mutually exclusive. 
In this paper, the analytical approach is founded on a process-view of relationships. Our interest is the behavior of actors over time (Pettigrew 1973, 1990). From this perspective, the long-term relationships that underlie collaborative schemes in the management of SESs should not be construed as entities, but rather as dynamic behavioral processes. As with all behavioral processes, they should be viewed as having outcomes, no matter how definable or indefinable those outcomes may be (Cousins 2002, Kinnaman and Bleich 2004). Such a perspective denotes how mutual adaptations in behavioral interactions take place between actors involved in collaboration. The adaptations provide premises on which collaborative actors rationalize their behavioral styles. We cannot, therefore, fully understand the behavioral style of an actor without an understanding of how it is linked to relational change.

\section{A FRAMEWORK FOR ANALYZING RELATIONAL CHANGE}

Change is an inherently pervasive variable in the process of managing long-term social relationships. According to Ford et al. (1998: 26), managing longterm relationships is not "a linear process of moving them in one direction towards some ideal state." It involves parties coping with discontinuous change in different circumstances at different times as they interact with each other. Most approaches to interpreting change in social relationships have been inadequate partly because they describe the development of relationships from initiation to stability. The concept of stability, however, has proved to be a difficult one for those researching collaboration (see Hakansson and Snehota 1995, Ford et al. 1998, Imperial 2005). As illustrated in this paper, most long-term relationships evolve through periods of instability. Also, it is important to note that not all relationships reach relative stability. Contemporary theoretical developments, therefore, stimulate a need to expand the range of frameworks to be used for interpreting change in social relationships.

We argue that a resilience approach offers a better perspective for the study of change in long-term social relationships, specifically those that underlie collaborative schemes in the management of SESs. We propose a conceptual framework that represents the phases of an adaptive cycle of long-term relationships in collaborative schemes. We postulate that long-term relationships, as complex behavioral processes, have a tendency of moving from an opportunistic state through collaborative and adversarial states into a tactical phase. The framework can be used to determine the potential for change based on the amount of relational capital and the degree of relational connectedness. These elements of a behavioral approach to relationships theory are proposed as a foundation for resilient social relationships.

\section{The Two Foundational Models}

The framework we propose builds on the works of Cousins (2002) (relationships theory) and Holling (1995) (resilience theory). Cousins (2002) proposes a model based on four types of inter-organizational relationships: adversarial, tactical, opportunistic, collaborative (see Fig. 1). His model provides an approach for viewing different types of interorganizational relationships using a matrix comprising two dimensions, dependency and certainty. The two dimensions influence how organizations make choices about what types of relationships are appropriate to deliver desired outputs. Although a number of approaches have been developed for classifying relationships (see Wood and Gray 1991, Huxham 1996, Imperial 2005), Cousins' (2002) model is particularly important in that it illustrates how organizations manage risks in relationships based on strategic decisions. Using game theory, the model provides a way for organizations to select and manage competitive relationships. The model, however, fails to explicitly expose the dynamic nature of longterm relationships, which is of utmost interest to this paper. As such, it may not be that useful for interpreting change in social relationships.

Holling (1995) proposes a "figure eight model" that was originally designed to interpret the dynamics and resilience of complex ecosystems, which are thought to go through phases of an adaptive cycle (see Fig. 2). The model is based on two dimensions, connectedness and amount of stored capital, which determine the exploitation, conservation, release, and reorganization phases of ecosystems. It is assumed that complex ecosystems move from rapid exploitation into a mature phase called conservation. As this phase develops, an ecosystem would become more rigid, thereby exposing the system to greater vulnerability. Eventually a disturbance would trigger sudden collapse, which 
Fig. 1. A model for viewing different types of inter-organizational relationships using a matrix comprising dependency and certainty dimensions (source: Cousins 2002).

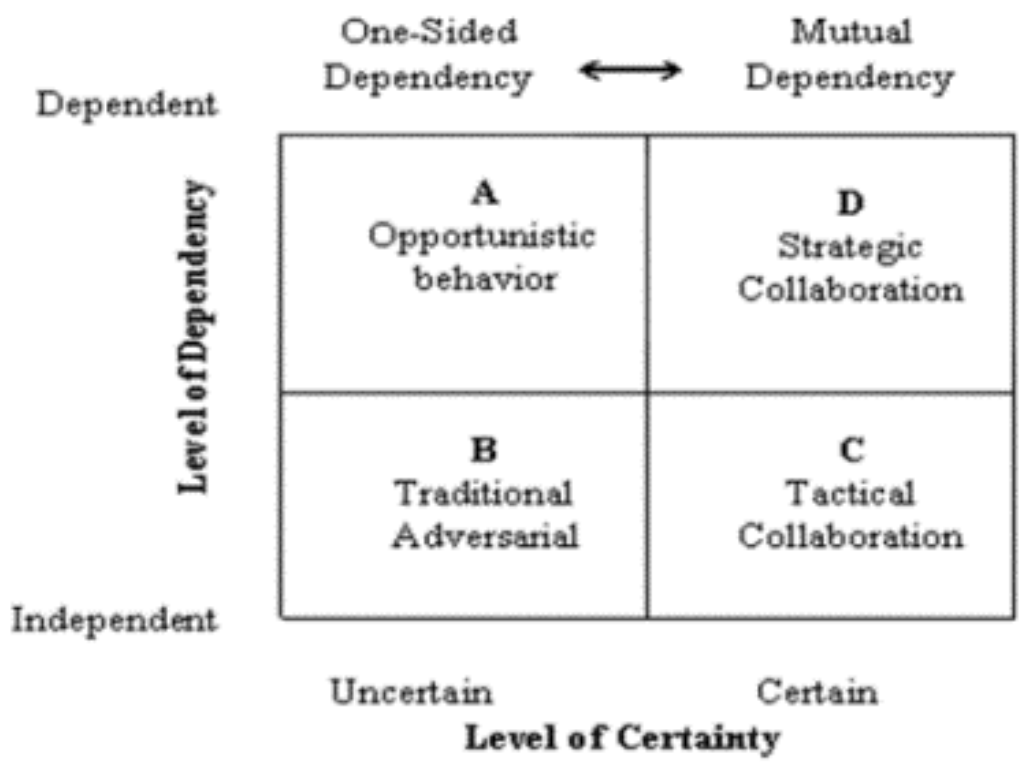

woukd be followed by a re-organization phase. Depending on particular circumstances, the system would then restart the adaptive cycle or move into a new configuration, as showed by the exit arrow at the left of Fig. 2. In this context, resilience refers to the amount of change a system can undergo while maintaining its function and structure (Holling 1973, Walker et al. 2006). It also entails the degree to which the system is able to self-organize and renew following disturbances (Berkes et al. 2003).

We acknowledge that a number of other people have also modified and applied Holling's model to a range of complex systems. Berkes and Folke(1998), for example, have mobilized a collection of interesting case studies that illustrate the application of the model. Also, Abel et al. (2006) provide a brief account of similar studies. According to resilience theory, only two conditions have to be met if we are to apply Holling's model to systems other than ecosystems. Firstly, such systems must be describable in dynamic terms and secondly, they must have potential to move into multiple states (Holling 1986, Berkes et al. 2003). We are of the view that the two conditions are met by most dynamic human processes, and thus the model can 
Fig. 2. The four ecosystem functions and the flow of events between them (source: Holling 1995).

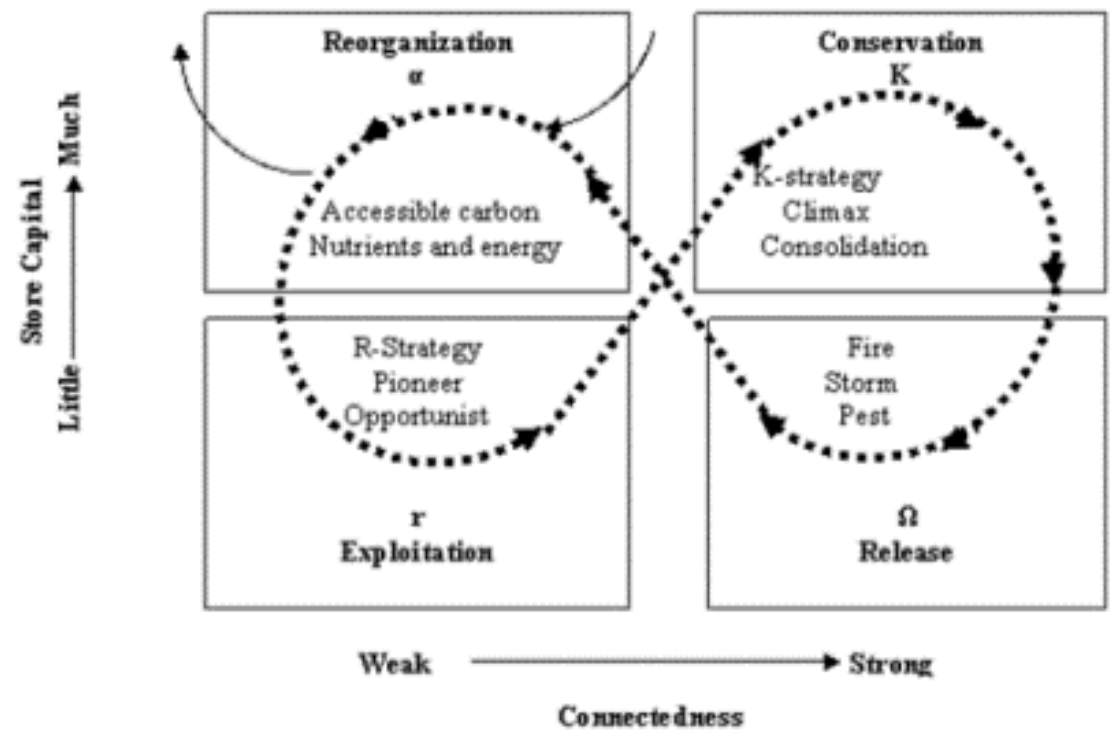

as well be applied to long-term social relationships. Given that humans have values and the ability to envision the future, we recognize that such an endeavor must be undertaken with extra precautions. This understanding, however, does not stop scientists from experimenting, learning, probing, and confronting uncertainty through innovative models (Walker et al. 2006). We need a variety of models to interpret the changing nature of the long-term social relationships that underlie collaborative schemes in the management of SESs. Accordingly, by incorporating the models of Holling (1995) and Cousins (2002) into a behavioral approach to relationships theory, the conceptual framework we propose in Fig. 3 can be used to examine change in such relationships, and to categorize and explain problematic episodes in collaborative schemes; thereby enabling focused corrective measures.

\section{Relational Change and Its Key Mediating Variables}

Relational change is defined by the degree of stability and instability of social relationships (Hakansson and Snehota 1995). Although the two 
Fig. 3. A framework based on relational capital and relational connectedness for analyzing change in long-term social relationships (adapted from Holling [1995] and Cousins [2002]).

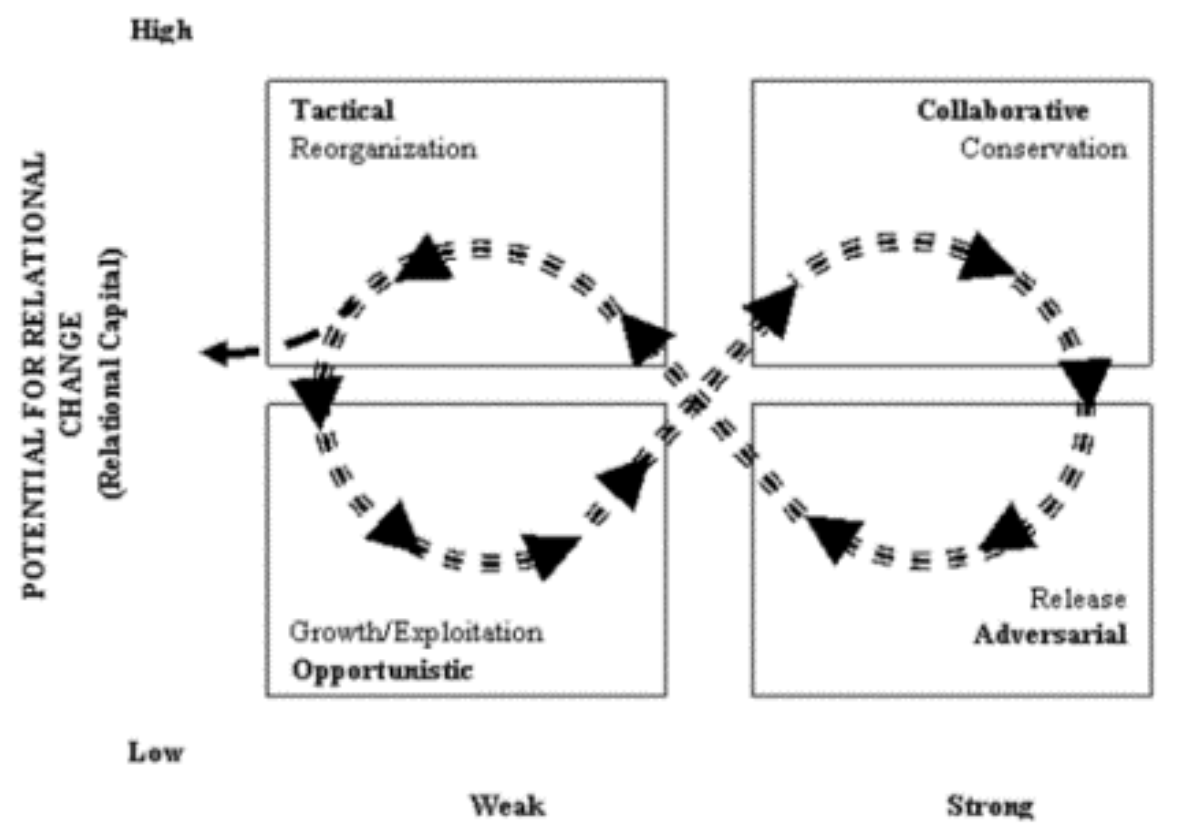

RELATIONAL CONNECTEDNESS

terms, stability and instability, may seem contradictory, in the context of long-term social relationships they coexist and are inseparable. Whereas the structure and function of collaborative schemes may appear relatively stable, the strength of underlying relationships changes discontinuously in response to multiple factors. Relationships may grow stronger or weaker to reflect the correlation between stability and instability. Thus, given the issues of bounded rationality (Williamson 1985), a collaborative actor has to jostle with unpredictable change surrounding the nature and character of the behavior of the other parties. For example, given the previous unimpressive sociopolitical record of most governments in the establishment of parks in southern Africa, some local communities were initially skeptical about governments' intention to genuinely involve them in collaborative wildlife management schemes. This led governments and donor agencies to invest financial resources in community projects to demonstrate their commitment to collaboration (Kiss 1990). In a way, these efforts helped change the nature of the long-term relationships between these actors. 
Although we are aware that change in long-term relationships can be initiated by either of the parties involved or by contextual factors, for the purposes of this paper we suggest that the potential for change is largely mediated by the amount of relational capital and degree of relational connectedness. We propose that the two mediating variables represent the extent of change that a collaborative scheme would have to experience before its underlying relationships move into different states. The two variables, through repeated interactions between parties, can generate multiple states for relationships in particular social environments (Axelrod 1984). Accordingly, we suggest that multiple states of relationships provide the substance of dynamic collaborative schemes in the management of SESs.

Relational capital refers to the stock of sociopsychological attributes of social relationships. Following Cullen et al. (2000), we consider trust and commitment as the two key attributes of relational capital. We propose that particular levels of these attributes mediate change in social relationships. Although the two attributes are not necessarily the only forms of social capital, most relationships theorists view them as particularly important determinants of the levels of relational capital. Trust is a sociopsychological state in which a party to a relationship adopts a belief that the other parties will not act against its interests (Luo 2002). As a sociopsychological state, it evolves from an actor's past experience, current interactions, and expectations. Commitment, on the other hand, refers to the energies and resources invested by parties in building long-term relationships. It denotes the extent to which parties believe that a relationship is worth expending energies and allocating resources on. Importantly, it evinces the readiness of parties to do more than is formally expected (Ireland et al. 2002).

Relational connectedness refers to the degree to which actors in social relationships are linked and the strength of links that mediate change in social relationships (Hakansson and Snehota 1995). For the purposes of this paper, actors in relationships are linked primarily through bonds, activities, and resources (Ford et al. 1998). The bonds dimension denotes the various ways in which actors perceive and respond to each other socially and professionally. The activities dimension refers to the connections among the activities of actors, and how such connections affect choices about how to share activities. The resource ties dimension evinces how the resources of actors are tied together and how such ties evolve as actors exchange or access each other's resources. Although the three are not necessarily the only dimensions for examining connectedness, they provide a useful approach for analyzing the substance of change in social relationships.

\section{The Adaptive Cycle of Long-term Social Relationships}

It is from the perspective of relational capital and relational connectedness that behavioral processes are vital in interpreting change in the long-term social relationships that underlie collaborative schemes. The two variables provide the basis of change to the extent that they enable relationships to grow, mature, collapse, and reorganize based on mutual adaptations in behavior. As shown in Fig. 3, long-term relationships go through phases of an adaptive cycle. The opportunistic state represents a phase during which new opportunities for collaboration are rapidly engaged. It is characterized as a growth state where actors capture easily accessible relational capital. Whereas the potential for change is lowered through engaging new opportunities, relational connectedness is, however, focused in terms of the identified new opportunities. Given the relatively low levels of relational capital, however, opportunities arise for parties to behave opportunistically (Williamson 1985). In Zambia, for example, the early years of collaborative wildlife management involving government, donor agencies, and local communities were characterized by instances when community representatives diverted project funds to personal purposes (Nkhata 2005). Although such practices can exist even within established collaborative schemes, this example demonstrates situations where an actor faces a counterpart who it may not know well or trust, and whose commitment might be questionable.

Growth in social relationships gives way to conservation as relational connectedness expands and relational capital is consolidated (Fig. 3). We refer to this emergent phase as the collaborative state where slow accumulation of relational capital and increased relational connectedness result in complex structures of interactions. Social relationships in this phase have the advantage of functioning through cooperative rather than market 
or bureaucratic instruments (Huxham 1996, Lawrence et al. 1999). Thus, it is possible in the collaborative phase to find parties who offer benefits to others even when they get nothing tangible in return. Even though such behaviors may encourage mutual cooperation, they are not necessarily altruistic in nature. Although it is impossible to predict the timescale on which particular relationships will attain this phase, it is important to note that cooperative behaviors in this phase are the emergent result of continuing interactions between parties (Axelrod 1984). Such interactions are based on exchanges that may not necessarily involve material artifacts, but also other intrinsic behavioral variables such as bribes, promises, gifts, rewards, and even sanctions. Empirical cases of emergent cooperative behavior have been recorded in collaborative wildlife management in Namibia (Jones 2001), watershed governance in the Lake Tahoe Basin (Imperial and Kauneckis 2003), and transnational river management in the Zambezi River Basin (Turton et al. 2005). In the United States, for example, repeated interactions between parties involved in the governance of Lake Tahoe generated changes in long-term intergovernmental relationships between public agencies and civil society actors (Imperial and Kauneckis 2003). The transformation of these relationships from being conflict-based to cooperative interactions resulted in the evolution of watershed governance in the Lake Tahoe Basin.

As the relationships progressively become more conservative, and thus more vulnerable to relational change, conservation gives way to release (Fig. 3). We refer to this emergent phase as the adversarial state when connectedness is strong but in which the capacity for change is low because of the complexity of expanded connectedness and a growth in adversarial behavior. Given that the relationships under this phase are founded on low levels of relational capital, the potential is high for them to generate conflict, which is associated with significant administrative and coordination costs (Lubell 2004). As Ford et al. (1998) suggest, although the sources of some conflicts are beyond the control of parties, the degeneration of most relationships into adversarial states can occur as a result of enduring patterns of interactions that give rise to the institutionalization of behavioral routines. At Lake Mburo National Park in Uganda, for example, behavioral routines that previously allowed the relationships between park staff and local communities to operate with low transactional costs were not questioned over time (Hulme and Infield 2001). As a result, parties paid less and less attention to such routines as holding regular meetings, sharing revenue from the park, compensating for loss of livestock to wild animals, and rewarding informers who reported illegal activities, thereby creating conditions for relationships to collapse. Notwithstanding the important effects of institutionalization, such moments are a common feature in long-term parkpeople relationships (Brechin et al. 2003).

Release gives way to reorganization, during which a collaborative scheme is reorganized through the emergence of new tactics and opportunities (Fig. 3). During the tactical phase, whereas the capacity for change is high due to the re-strengthened relational capital, connectedness is low as it is regaining focus. Depending on particular conditions, reorganization may result in opportunism once again, thereby triggering the system into yet another adaptive cycle. As the exit arrow at the left of Fig. 3 suggests, reorganization may also lead to a shift into a new configuration of less or more cooperative behaviors. Reorganization in long-term relationships is evidenced in practice in many ways, including the crafting of local rules for the onshore traditional fisheries in Alanya, Turkey (Ostrom 1990), the institutionalization of science practices in the National Estuary Program in the United States (Lubell 2004), and the establishment of water commissions in southern Africa (Turton et al. 2005).

Based on the foregoing, and building on existing literature, it is suggested that long-term relationships vary as behaviors evolve over time. They change into different states, which shape the nature of collaborative arrangements. Multiple interactions between parties generate different states through which collaborative actors rationalize their behavioral styles. It is important to note that, although the four states of relationships are distinguishable, in reality they find expression simultaneously and to different extents at any stage of exchanges between actors. It should also be realized that relationships do not necessarily move into each of these states in a predetermined manner. Some relationships will, of course, fail to strengthen, whereas others will be short-lived because of various factors. The conceptual framework in Fig. 3, therefore, should be construed as a representation of relationships that are long lasting and pass through situations that are potentially problematic in reality. 


\section{CONCLUSION: RESILIENCE IN LONG- TERM SOCIAL RELATIONSHIPS}

We have attempted in this paper to provide a social relationships perspective of collaboration in the management of SESs. In so doing, we have provided a conceptual premise for understanding the dynamics of long-term social relationships that underlie collaborative processes. Arguably, a resilience approach offers a better perspective to the study of change in long-term relationships. An analysis of resilient social relationships requires an understanding of the complexity and extent of relational change. The conceptual framework we have developed highlights the elements of a behavioral approach as a foundation for resilient social relationships. The resilience of long-term social relationships denotes the competence of actors to maintain relationships in socially desirable states and to allow relationships to reorganize following disturbances. In other words, relational resilience enhances the competence of actors to cope with change in various situations. It is important, however, to realize that not all aspects of resilience are necessarily essential. This is because some undesirable states of social relationships can be highly resilient. For example, actors would continue to invest considerable effort in dealing with adversarial partners even when there are no apparent desirable outcomes. In such cases, it might be important to identify the behavioral processes that help maintain such undesirable relationships.

The conceptual framework is designed to illustrate how actors can build resilient collaborative relationships based on the levels of relational capital and degree of relational connectedness. It shows how actors can make decisions about how to shape the nature and quality of long-term social relationships. Based on the two variables (relational capital and relational connectedness), actors can either change or maintain forms of relationships that buttress the interests of all parties. We postulate that collaborative schemes in the management of SESs largely fail due to incompatibilities between the two variables. When these variables are not effectively managed, misunderstandings and disagreements between actors emerge. To that end, the framework enables actors to categorize forms of relationships and identify those behaviors that exert negative influence on collective decision-making processes. As such, the framework allows actors to determine where remedial interventions may be required. The framework not only allows actors to understand consistent behavioral patterns, but also provides a premise on which collective decision-making processes can be managed in collaborative schemes.

We have illustrated that multiple states of relationships provide the substance of dynamic collaborative schemes. Whereas change in longterm relationships comes about as a result of behavioral processes involving the two variables, change also feeds back to influence the behavioral processes (Axelrod 1984, Bardach 2001). As such, the two variables not only provide a wide range of possible pathways for the future development of social relationships, but also enable behavioral learning through the building, upgrading, and enriching of the knowledge stores of actors. Learning shapes the actors' ways of behaving in relationships by aligning and fostering their capacity to deal with relational change (Johnson et al. 2004). To that extent, the amount of change that social relationships can undergo is important in determining how actors cope with change when it is almost impossible to predict with accuracy future states of social relationships. And this is a function of resilience.

The essence of the framework is to facilitate understanding and building of resilient social relationships for effective collaboration through interpreting and managing relational change. Without a sound theoretical underpinning, we risk omitting the critical determinant variables that can help explain and predict effective collaboration. In this context, the centrality of relationship theory in the process of integrating human behavioral sciences in SES research cannot be overemphasized. Our framework, however, should be construed as a related set of explicit assumptions that can be used to better understand and improve collaboration. We acknowledge that our assumptions are inherently incomplete and will evolve as new understandings of collaboration emerge. Issues that are strongly related to resilience in collaborative arrangements form the basis for the assumptions. We believe that effective collaboration in the management of SESs should be founded on resilient social relationships.

Responses to this article can be read online at: http://www.ecologyandsociety.org/vol13/iss 1/art2/responses/ 


\section{Acknowledgments:}

This work was supported by the Ford Foundation CBNRM Program at the Centre for Environment, Agriculture, and Development, University of KwaZulu-Natal in South Africa. The authors would like to thank Kevin Rogers (Centre for Water in the Environment, Witwatersrand University) and Harry Biggs (South African National Parks/Kruger National Park) for their profound insights during the preparation of this paper. The Zambia Wildlife Authority is also thanked for its support to Abraham Nkhata.

\section{LITERATURE CITED}

Abel, N., D. H. M. Cumming, and J. M. Anderies. 2006. Collapse and reorganization in socialecological systems: questions, some ideas, and policy implications. Ecology and Society 11(1): 17. [online] URL: http://www.ecologyandsociety.org/vol11/ iss $1 / \operatorname{art} 17 /$.

Axelrod, R. 1984. The evolution of cooperation. Basic Books, Inc., New York, New York, USA.

Bardach, E. 2001. Developmental dynamics: collaboration as an emergent phenomenon. Journal of Public Administration Research and Theory 11 (2):149-164

Berkes , F., J. Colding, and C. Folke, editors. 2003. Navigating social-ecological systems: building resilience for complexity and change. Cambridge University Press, Cambridge, UK.

Berkes, F., and C. Folke, editors. 1998. Linking social and ecological systems for resilience and sustainability: management practices and social mechanisms for building resilience. Cambridge University Press, Cambridge, UK.

Blau, P. M. 1964. Exchange and Power in Social Life. John Wiley and Sons, Inc., New York.

Blau, P. M. 1987. Micro-process and macrostructure. In K. S. Cook, editor. Social exchange theory. Sage Publications, Inc., Newbury Park, California, USA.
Blumenthal, D., and Jannink, J. L. 2000. A classification of collaborative management methods. Conservation Ecology 4(2):13 [online] URL: http:/ /www.consecol.org/vol4/iss2/art13/.

Brechin, S. R., P. Wilshusen, C. L. Fortwangler, and P. C. West, editors. 2003. Contesting nature: promoting international biodiversity with social justice in the twenty-first century. State University of New York Press, Albany, New York, USA.

Cousins, P. D. 2002. A conceptual model for managing long-term inter-organizational relationships. European Journal of Purchasing and Supply Management 8:71-82.

Cullen, J. B., J. L. Johnson, and T. Sakano. 2000. Success through commitment and trust: the soft side of strategic alliance management. Journal of World Business 35(3):223-240.

Emerson, R. M. 1987. Towards a theory of value in social exchange. In S. K. Cook, editor. Social exchange theory. Sage Publications, Inc., Newbury Park, California, USA.

Folke, C., S. Carpenter, T. Elmqvist, L. Gunderson, C. S. Holling, B. Walker, J. Bengtsson, F. Berkes, J. Colding, K. Danell, M. Falkenmark, L. Gordon, R. Kasperson, N. Kautsky, A. Kinzig, S. Levin, K. Maler, F. Moberg, L. Ohlsson, P. Olsson, E. Ostrom, W. Reid, J. Rockstrom, H. Savenije, and U. Svedin. 2002. Resilience and sustainable development: building adaptive capacity in a world of transformations. Scientific Background Paper on Resilience for the Process of the World Summit on Sustainable Development on Behalf of the Environmental Advisory Council to the Swedish Government.

Ford, D., L. Gadde, H. Hakansson, A. Lundgren, I. Snehota, P. Turnbull, and D. Wilson. 1998. Managing business relationships. John Wiley, New York, New York, USA.

Granovetter, M. 1985. Economic action and social structure: the problem of embeddedness. American Journal of Sociology 91:481-510.

Granovetter, M. 1990. The old and the new economic sociology. In $\mathrm{R}$. Friedland and A. Robertson, editors. Beyond the marketplace. De 
Gruyter, New York, New York, USA.

Hakansson, H., and I. Snehota. 1995. Developing relationships in business networks. Thompson, London, UK.

Hall, W. 1995. Managing cultures: making strategic relationships work. John Wiley, Chichester, UK.

Hardy, C., and N. Phillips. 1998. Strategies of engagement: lessons from the critical examination of collaboration and conflict in an organizational domain. Organization Science 9(2):217-230.

Holling, C. S. 1973. Resilience and stability of ecological systems. Annual Review of Ecology and Systematics 4:1-23.

Holling, C. S. 1986. The resilience of terrestrial ecosystems: local surprise and global change. Pages 292-317 in W. C. Clark and R. E. Munn, editors. Sustainable development of the biosphere. Cambridge University Press, Cambridge, UK.

Holling, C. S. 1995. What barriers? What bridges? Pages ??? in L. H. Gunderson, C. S. Holling, and S. S. Light, editors. Barriers and bridges to the renewal of ecosystems and institutions. Columbia University Press, New York, New York, USA.

Hulme, D., and M. Infield. 2001. Community conservation, reciprocity and park-people relationships: Lake Mburo National Park, Uganda. Pages ??? in D. Hulme and M. Murphree, editors. African wildlife and livelihoods: the promise and performance of community conservation. James Currey Ltd., Oxford, UK.

Hutchison, E. D. 2003. Dimensions of human behavior. Sage Publications, Thousand Oaks, California, USA.

Huxham, C., editor. 1996. Creating collaborative advantage. Sage Publications, London, UK.

Imperial, M. T. 2004. Collaboration and performance management in network settings: lessons for three watershed governance efforts. IBM Center for the Business of Government, Washington, D.C., USA.

Imperial, M. T. 2005. Using collaboration as a governance strategy: lessons form six watershed management programs. Administration and Society
37(3):281-320.

Imperial, M. T., and D. Kauneckis. 2003. Moving from conflict to collaboration: lessons from the Lake Tahoe experience. Natural Resources Journal 43(4):1009-1005.

Ireland, R. D., M. A. Hitt, and D. Vaidyanath. 2002. Alliance management as a source of competitive advantage. Journal of Management $\mathbf{2 8}$ (3):413-446.

Johnson, J. L., R. S. Sohi, and R. Grewal. 2004. The role of relational knowledge stores in inter-firm partnering. Journal of Marketing 68 (July):21-36.

Jones, B. 2001. The evolution of a communitybased approach to wildlife management at Kunene, Namibia. Pages ??? in D. Hulme and M. Murphree, editors. African wildlife and livelihoods: the promise and performance of community conservation. James Currey Ltd, Oxford, UK.

Kinnaman, M. L., and M. R. Bleich. 2004. Collaboration: aligning resources to create and sustain partnerships. Journal of Professional Nursing 20:310-322.

Kiss, A., editor. 1990 . Living with wildlife: wildlife resource management with local participation in Africa. Technical Paper 130. Africa Technical Department series. World Bank, Washington, D.C., USA.

Knoke, D. 1990. Political networks: the structural perspective. Cambridge University Press, New York, New York, USA.

Lawrence, T. B., N. Phillips, and C. Hardy. 1999. Watching whale watching: exploring the discursive foundations of collaborative relationships. The Journal of Applied Behavioral Sciences 35(4):479_ 502.

Lubell, M. 2004. Resolving conflict and building cooperation in the National Estuary Program. Environmental Management 33(5):677-691.

Luo, Y. 2002. Building trust in cross-cultural collaborations: towards a contingency perspective. Journal of Management 28(5):669-694.

Newman, L., and A. Dale. 2005. Network structure, diversity and proactive resilience: a 
response to Tompkins and Adger. Ecology and Society 10(1):r2. [online] URL: http://www.ecolog yandsociety.org/vol10/iss1/resp2/.

Nkhata, A. B. 2005. Devolution and natural resources management in Zambia: transforming rural communities into gamekeepers with authority. Pages ??? in Dzingirai and Breen, editors. Confronting the crisis in community conservation: case studies from Southern Africa. University of KwaZulu-Natal Press, Pietermaritzburg, South Africa.

Ostrom, E. 1990. Governing the commons: the evolution of institutions for collective action. Cambridge University Press, New York, New York, USA.

Ostrom, E. 1998. A behavioral approach to the rational choice theory of collective action: presidential address, American Political Science Association, 1997. American Political Science Review 92(1):1-22.

Pettigrew, A. M. 1973. The politics of organizational decision making. Tavistock, London, UK.

Pettigrew, A. M. 1990. Longitudinal field research on change: theory and practice. Organizational Science 1(3): 267-292.

Phillips, N., T. B. Lawrence, and C. Hardy. 2000. Inter-organizational collaboration and the dynamics of institutional fields. Journal of Management Studies 37(1):23-43.

Selin, S. 2004. Natural resource partnerships. Pages ??? in M. J. Manfredo, J. J. Vaske, B. L. Bruyere, D. R. Field, and P. J. Brown, editors. Society and natural resources: a summary of knowledge. Prepared for the $10^{\text {th }}$ International Symposium on Society and Resource Management, Keystone, Colorado, USA.

Tompkins, E. L. and W. N. Adger. 2004. Does adaptive management of natural resources enhance resilience to climate change? Ecology and Society 9(2):10. [online] URL: http://www.ecologyandsociety. org/vol9/iss $2 /$ art10/.

Turton, A., A. Earle, D. Malzbender, and P. J. Ashton. 2005. Hydro-political vulnerability and resilience along Africa's international waters.
United Nations Environment Program, Hydropolitical Vulnerability and Resilience along International Waters, Division of Early Warning and Assessment-North America, Sioux Falls, South Dakota, USA.

Walker, B., S. Carpenter, J. Anderies, N. Abel, G. Cumming, M. Janssen, L. Lebel, J. Norberg, G. D. Peterson, and R. Pritchard. 2002. Resilience management in social-ecological systems: a working hypothesis for a participatory approach. Conservation Ecology 6(1):14. [online] URL: http: //www.consecol.org/vol6/iss1/art14/.

Walker, B. H., L. H. Gunderson, A. P. Kinzig, C. Folke, S. R. Carpenter, and L. Schultz. 2006. A handful of heuristics and some propositions for understanding resilience in social-ecological systems. Ecology and Society 11(1):13. [online] URL: http://www.ecologyandsociety.org/vol11/iss1/ art13/.

Williamson, O. E. 1985. The economic institutions of capitalism: firms, markets and relational contracting. The Free Press, New York, New York, USA.

Wondolleck, J. M., and S. L. Yaffee. 2000. Making collaboration work: lessons from innovation in natural resource management. Island Press, Washington, D.C., USA.

Wood, D. J. and B. Gray. 1991. Towards a Comprehensive Theory of Collaboration. The Journal of Applied Behavioral Sciences 27(2):139162. 